\title{
Implementasi BAS (Building Automatic System) Menggunakan Replikasi Prototype Control Lighting Dengan Mikrokontroller Arduino
}

\author{
Tata Sutabri $^{\text {() }}{ }^{*}$, Purnomo $^{2)}$, Yohanes Bowo Widodo ${ }^{3)}$ \\ ${ }^{1)}$ Fakultas Teknologi Informasi, Universitas Respati Indonesia \\ 2) 3) Program Studi Teknik Informatika, Universitas Mohammad Husni Thamrin \\ ${ }^{*}$ Correspondence Author: tata.sutabri@gmail.com , Jakarta, Indonesia \\ DOI: https://doi.org/10.37012/jtik.v7i1.501
}

\begin{abstract}
Abstrak
Efisiensi, efektifitas, penghematan energi listrik telah menjadi topik penelitian yang menarik banyak peneliti sekarang ini. Model teknologi telah banyak yang diusulkan untuk meningkatkan efektifitas dan hemat energi listrik bagi Perusahaan. Salah satu contohnya adalah model BAS (building automatic system) mengunakan perangkat Arduino. Pada penelitian ini, implementasi system BAS menggunakan replikasi prototype control lighting dengan Mikrokontroller Arduino. Penelitian dilakukan pada PT. Betawi Jaya Mandiri. Sistem BAS yang diusulkan dikendalikan secara terpusat oleh sebuah komputer. Komputer dapat mengontrol hidup atau matinya lampu dengan menggunakan Ardiuno Client. Komputer juga dapat mengetahui arus listrik yang terpakai mengunakan arduino server. Kelebihan alat ini dapat mengontrol semua lampu atau beban lain dalam gedung bertingkat dari satu tempat yaitu server berupa local host. Penerapan sistem BAS pada PT. Betawi Jaya mandiri menjadikan operasional pemantauan gedung sangat efektif. Dengan sistem BAS ini jam operasional bisa diatur dengan mudah dengan kontrol dari laptop melalui tombol on/off. Seluruh lampu di setiap lantai bisa dipantau dengan baik.
\end{abstract}

Kata kunci: Arduino, Smart Building, Building Automatic System, Local Host

\begin{abstract}
Efficiency, effectiveness, saving electrical energy has become a research topic that attracts many researchers nowadays. Many technology models have been proposed to increase the effectiveness and save electrical energy for the Company. One example is the BAS (building automatic system) model using the Arduino device. In this study, the implementation of the BAS system uses a lighting control prototype replication with an Arduino microcontroller. The research was conducted at PT. Betawi Jaya Mandiri. The proposed BAS system is controlled centrally by a computer. The computer can control the light on or off by using the Ardiuno Client. The computer can also find out the electric current used using the Arduino server. The advantage of this tool is that it can control all lights or other loads in a multi-storey building from one place, namely the server in the form of a local host. The implementation of the BAS system at PT. Betawi Jaya independently makes building monitoring operations very effective. With this BAS system, operating hours can be easily adjusted by controlling the laptop via the on / off button. All lights on each floor can be monitored properly.
\end{abstract}

Keywords: Arduino, Smart Building, Building Automatic System, Local Host

\section{PENDAHULUAN}

Di era perkembangan teknologi yang semakin canggih dan energi didunia semakin terbatas, masalah efesiensi, kemudahan dan kecepatan operasi adalah aspek penting dari sebuah operasional gedung, terutama pada perusahaan-perusahaan skala menengah ke atas. 
Control lighting merupakan solusi yang digunakan perusahaan untuk mempercepat dan memperlancar pekerjaan di perusahaan tersebut.

Di sebuah perusahaan, bangunan Gedung terdiri dari beberapa tingkat (lantai) hingga mencapai puluhan lantai. Lampu penerangan selalu ada di setiap lantai dan jumlahnya banyak sekali sehingga sangat tidak efektif bila di operasikan secara manual menggunakan saklar. Pemadaman menggunakan saklar merupakan operasi yang lambat, karena lokasi saklar yang berjauhan. Alat yang bernama Smart builliding berbasis micro controller Arduino dapat mengatur lampu dari jarak jauh, dan dapat dipusatkan di satu tempat yang disebut ruang control. Alat ini dapat dioperasikan dengan mudah sehingga membantu petugas meringankan pekerjaan. Jangkauan control sangat luas dengan biaya yang relatif terjangkau.

\section{METODE}

Pada Gambar 1, lampu dibagi dalam beberapa zone dari zone A sampai zone P. Ada 16 zone atau 16 group. Jika terjadi hubungan pendek atau korsleting pada salah satu lampu, hanya 1 zone saja yang padam dan MCB (Miniature Circuit Breaker) akan Trip pada zone yang terjadi korsleting listrik. Pada gambar 1 saklar diletakkan di Ruang Panel supaya aman dan hanya teknisi saja yang mengontrol penerangan gedung pada setiap lantai. Jam operasional gedung pada pukul 09.30 WIB - 20.00 WIB, karena posisi saklar berada di masing-masing lantai dan lantai gedung PT. Betawi Jaya Mandiri sampai 11 lantai sehingga memakan waktu, atau tidak efisien untuk melakukan kegiatan operasional gedung.

Metode pemecahan masalah seperti berikut:

1) Lighting pada setiap lantai di grouping sesuai zona dan di beri label pada setiap zona.

2) Saklar diganti oleh Sistem BAS (Building automatic Sistem).

3) Dari setiap Lantai Lighting dipusatkan dan di control di satu tempat yang strategis supaya mudah untuk di operasikan.

Building Automation System (BAS) adalah sebuah pemrograman, komputerisasi, Intelligent Network dari peralatan elektronika yang mengontrol sistem mekanis dan sistem penerangan dalam sebuah gedung. Admin adalah teknisi yang bertanggung jawab secara penuh dalam sistem operasional gedung untuk menggontrol dan menyalakan sistem penerangan gedung dan tidak lagi menyalakan penerangan secara manual di saklar pada setiap lantai. 


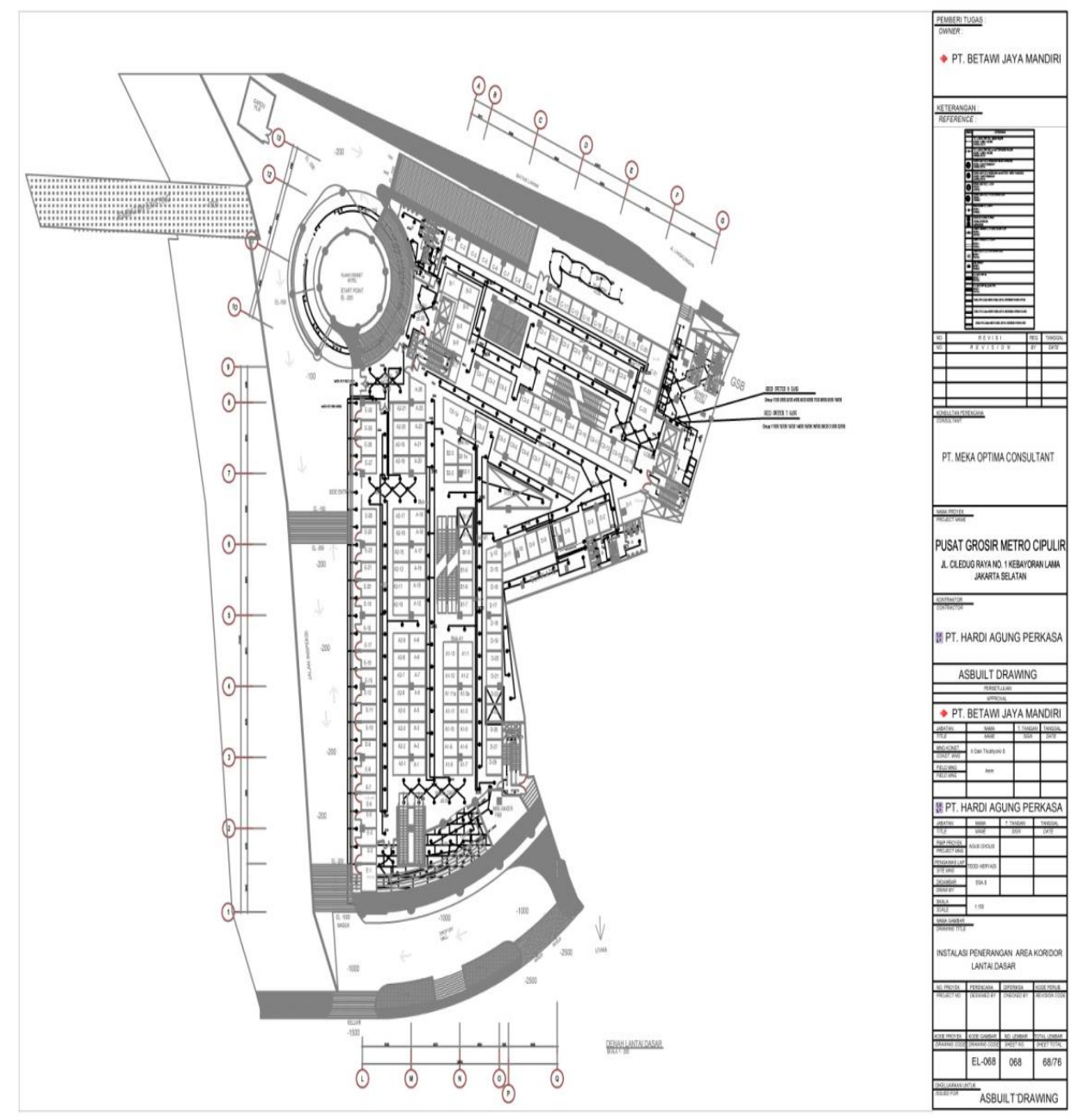

Gambar 1. Denah Gedung Lantai Dasar PT. Betawi Jaya Mandiri

Alur kontrol dari perangkat pada gambar 2 adalah sebagai berikut:

1. Laptop mengirim data string ke Ip Arduino client melewati switch

2. Fungsi swich menghubungkan Antara laptop dengan Ethernet shield yang berada di arduino client maupun di arduino server

3. Ethernet shileld/modul LAN berfungsi untuk mengkoneksikan Arduino dengan jaringan Ethernet menggunakan kabel utp cat 5e ke switch

4. Arduino Client berfungsi sebagai pengontrol relay berdasarkan data yang dikirim dari laptop dan arduino client menggirimkan sinyal digital ke pin digital arduino server

5. Relay berfungsi sebagai pengontrol beban berdasarkan sinyal yang dikirim oleh Arduino Client

6. Lampu (beban) sebagai indikator kalau perangkat itu sedang on atau off 
7. Sensor arus berfungsi sebagai membaca besaran arus listrik yang dilewati oleh sebuah beban contoh beban seperti lampu ataupun motor listrik. Sensor arus berfungsi mengirimkan sinyal analog ke pin analog arduino server

8. Arduino server berfungsi menerima dan membaca sinyal digital dari ardiuno client serta menerima sinyal analog dari sensor arus dan mengubah jadi besaran arus listrik kemudian pin digital arduino server mendapatkan nilai high/low kemudian mengirim data string ke database laptop melalui Ethernet shield

9. Ethernet shield arduino server mengirimkan data string ke laptop melalui switch

10. Laptop menampilkan data yang dikirim arduino server melalui switch.

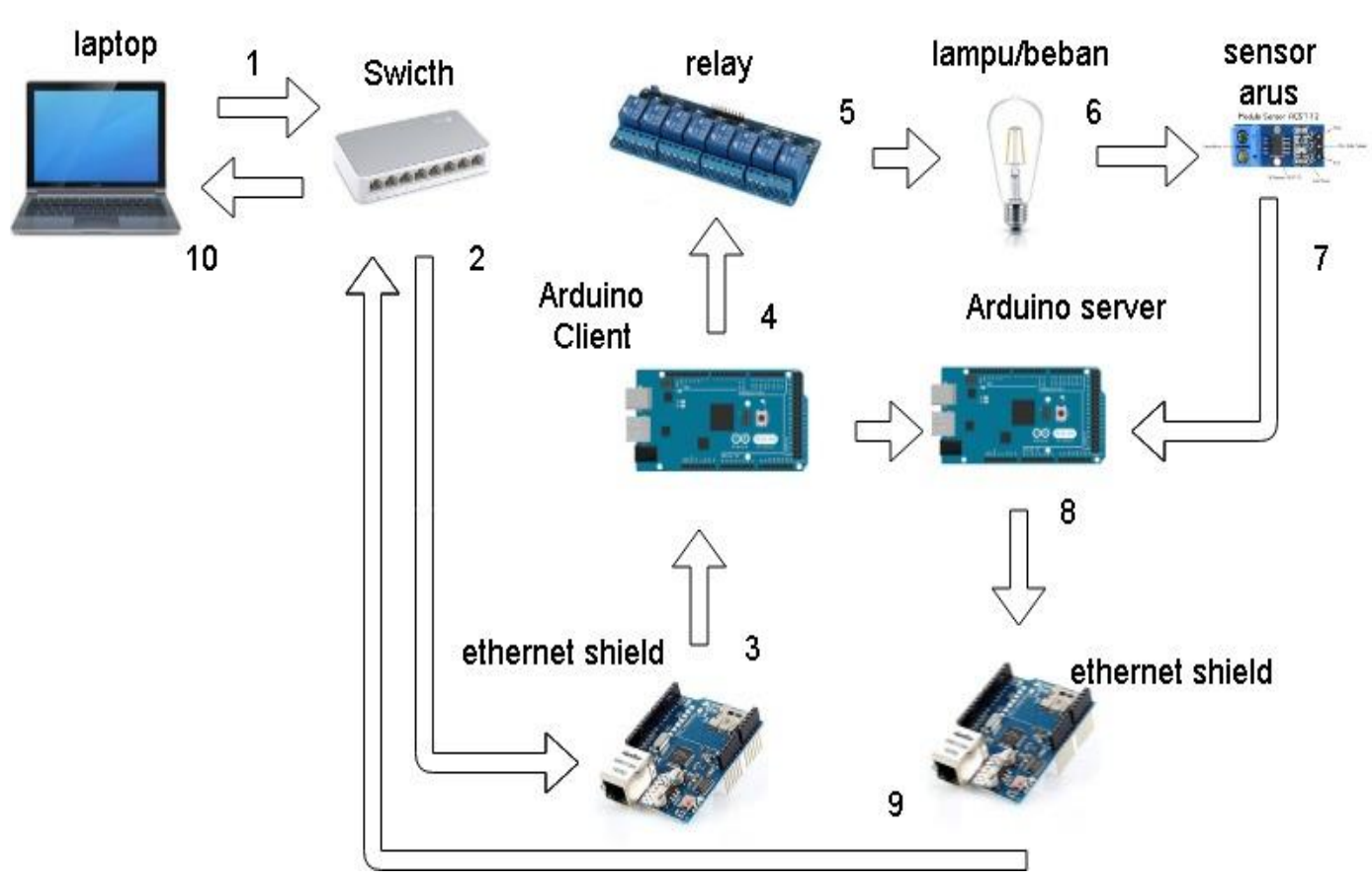

Gambar 2. Alur Sistem Kontrol Perangkat

Pada gambar 3 digambarkan rangkaian control pada sistem BAS. Pada gambar ini terdapat 2 Arduino Atmega dan 2 ethernet shield dan relay 8 port dan 4 port, serta menggunakan 2 buah sensor arus. Juga digunakan kabel jumper untuk menghubungkan perangkat tersebut. 


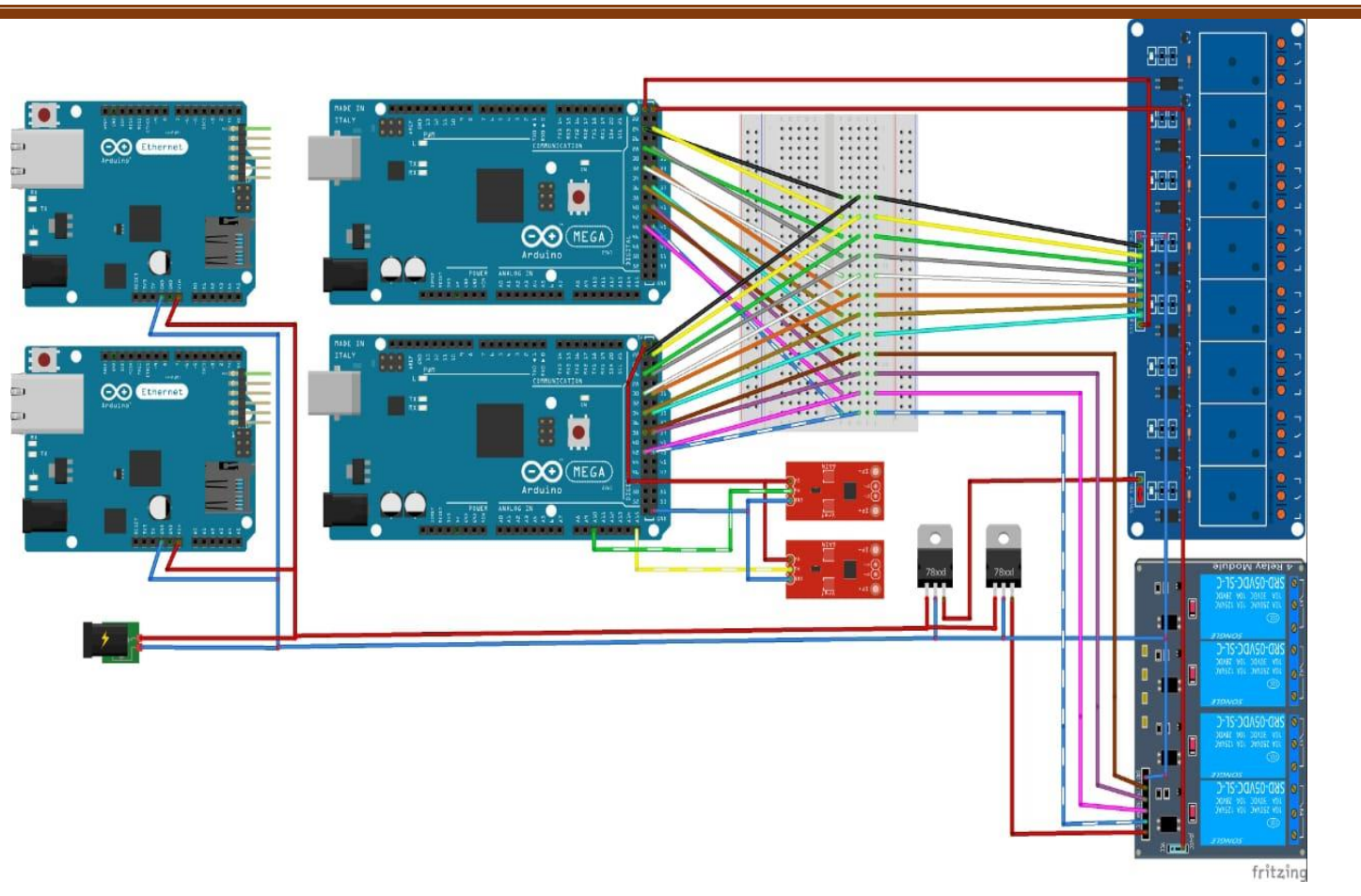

Gambar 3. Rangkaian Kontrol

\section{HASIL DAN PEMBAHASAN}

Pada gambar 4 ditampilkan halaman awal untuk masuk ke sistem BAS. Pemakai harus login dahulu supaya menghindari penggunaan oleh orang yang tidak berwenang. Teknisi operasional lah yang berhak mengontrol dan mengendalikan sistem operasional penerangan gedung dan memiliki akses untuk mengontrol lampu gedung tersebut.

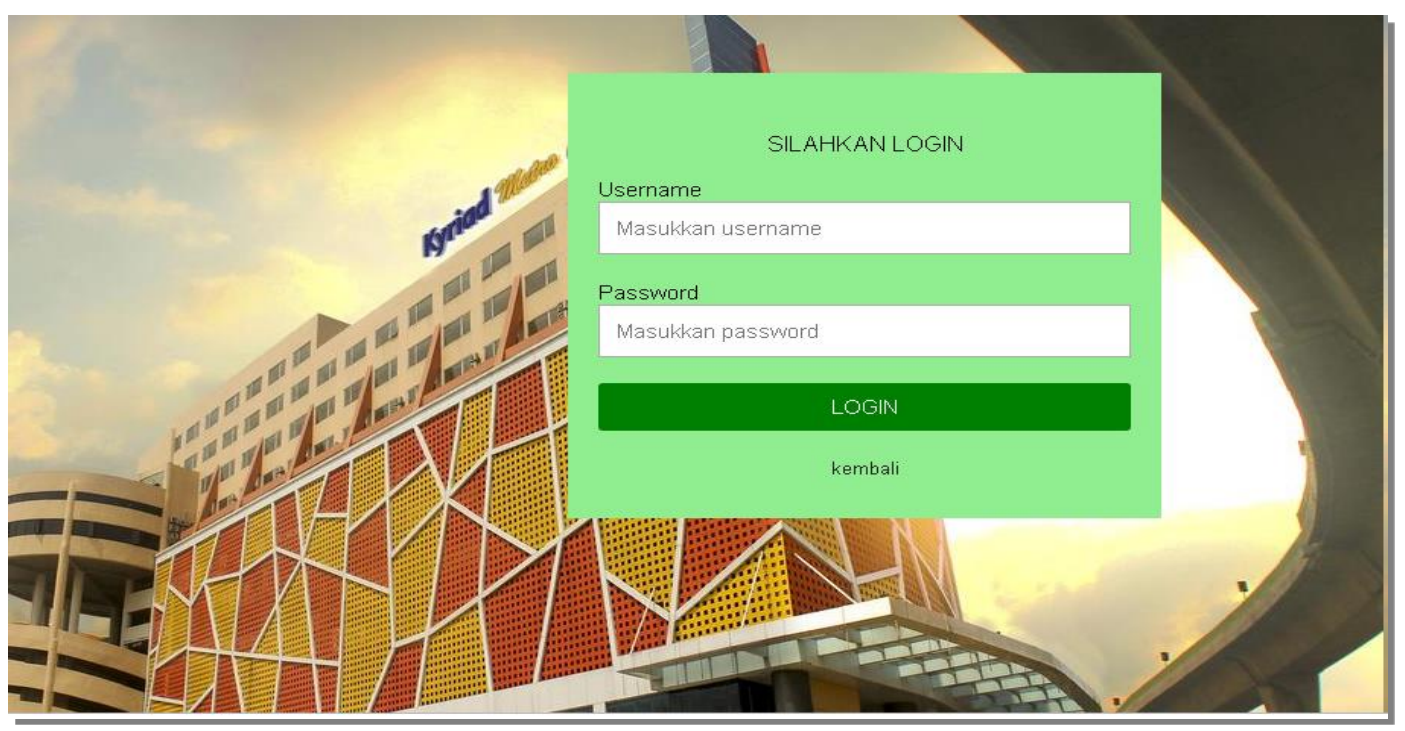

Gambar 4. Halaman Login 
Pada gambar 5 ditunjukkan tampilan halaman utama. Di halaman tersebut seorang user atau teknisi operasional mengontrol lampu, fcu, stopkontak dan kontaktor tetapi lebih spesifik dapat menuju ke lighting per zona setiap lantai. Disediakan 8 zona dalam satu lantai. Jika dibutuhkan efesiensi dalam pemakaian, biasa dikendalikan seluruh lantai yang ada di gedung tersebut.

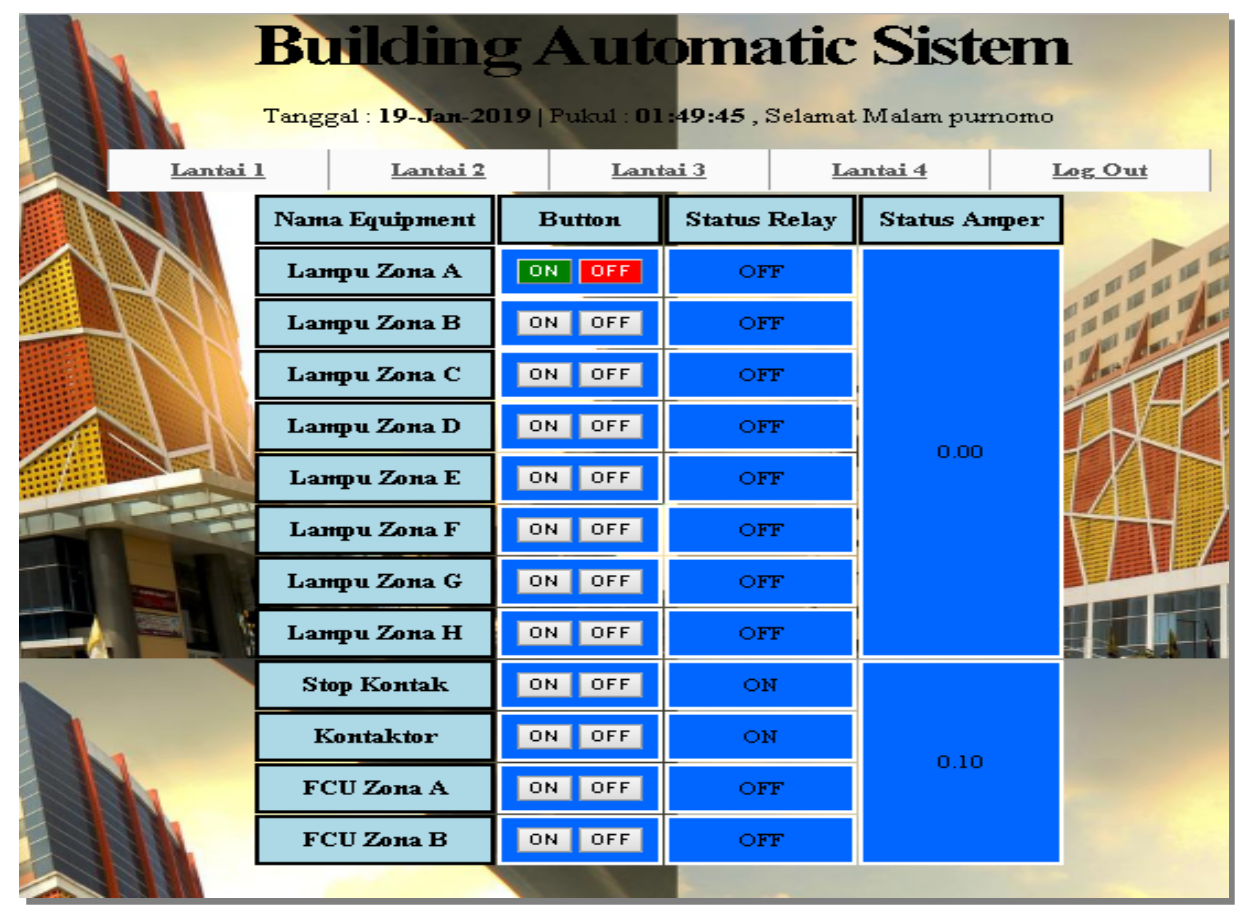

Gambar 5. Tampilan Kontrol

\section{KESIMPULAN DAN REKOMENDASI}

Berdasarkan pengamatan di lapangan dan uraian mengenai proses berjalan sistem pada PT Betawi Jaya mandiri maka diambil kesimpulan sebagai berikut :

Bahwa penerapan Implementasi Sistem BAS pada PT Betawi Jaya mandiri sangat efektif dalam operasional Gedung. Dengan Sistem BAS ini jam operasional bisa berjalan efektif dan di kontrol dari laptop melalui tombol button on/off seluruh lantai bisa terkendali dengan baik

Berdasarkan kesimpulan diatas, maka direkomendasikan beberapa hal berikut:

Agar sistem BAS dapat berjalan dengan baik, maka perlu update setiap saat, perbaikan, pemeliharaan yang dilakukan secara berkala supaya perangkat berfungsi dengan baik. 
Website pengontrol sebaiknya dikembangkan lagi, agar dalam segala hal yang berhubungan dengan pelaksanaan Operasional gedung berjalan efektif, sehingga teknisi yang berada di gedung bisa fokus saat terjadi masalah pada sistem kelistrikan. Dengan menggunakan sistem komputerisasi maka kendala-kendala dalam kecepatan kerja dan efesiensi serta keamanan data diharapkan lebih terjamin dan lebih cepat.

\section{REFERENSI}

Hari Santoso. 2015. "Panduan praktis Arduino untuk pemula". Trenggalek. From http://www.elangsakti.com/2015/07/ebook-panduan-Praktis-arduino-untukpemula.html/ Di akses pada 07 Juli 2018.

Hari Santoso.2017. "Moster Arduino". Malang http://www.elangsakti.com/2017/09/ebook-Moster-arduino.html/ Di akses pada 19 Juli 2018.

Abdul Kadir .2016. "Stratc for Arduino (S4A) Panduan untuk mempelajari Electronika dan pemrograman". Yogyakarta: ANDI

Mochamad Fajar Wicaksono, Skom., M.kom. Hidayat, S.kom., M.T. 2017. "Mudah Belajar Mikrokontroler Arduino". Bandung: Informatika.

Fathansyah, 2018. "Basis data". Bandung: Informatika.

Edy Winarno ST, M.Eng. Ali Zaki. Smit Dev Community. 2013. "Membuat sendiri jaringan computer". Jakarta: PT Elex Media Komputindo.

Abdul Kadir. 2018. "Dasar Pemrograman Internet untuk Proyek Berbasis Arduino". Yogyakarta: ANDI

Hidayatullah, P, \& Kawistara, J. K. 2017. "Pemrograman Web". Bandung: Informatika. Alexander, Fk. Sibero, 2013. "Web Programing Power Pack". Yogyakarta: Mediakom.

Supomo, \& Putratama. V. 2016. "Pemrograman Web dengan menggunakan Php dan Framework codeigniter". Yogyakarta: Deepublish

Muhammad, Sadeli. 2013. "Dreamweaver Cs6 untuk orang awam". Palembang: Maxikom 